\title{
A Study On Deep Learning Based Real Time Road information Monitoring Device for Emergency Vehicle Guidance
}

\author{
Seona Park ${ }^{+}$, Junghan Ha, Muwook Pyeon, Wonwoo Jung \\ Konkuk University, Republic of Korea
}

\begin{abstract}
This study is to secure the golden time for emergency vehicles, especially to shorten time in narrow roads. These days, in Korea the black box install rate is over $88.9 \%$ and it shows that Koreans use black box much more than other countries. Through this study we can analyze the road situation by collecting the data through the black box and transmit it to the server. And not just guiding the emergency vehicle to the shortcut but to the optimal route when they pass through alleys. Finally we could suggest the solution for the emergency vehicle to be in golden time. For this study we used Raspberry-Pi and Yolo v3 algorithm. There were difference between analyzing the image and the video and concluded that the video take much more time due to the transmission delay and data size.
\end{abstract}

Keywords: Deep Learning, Emergency Vehicle Guidance, Real Time Road Information, Yolo v3

\section{Introduction}

It is important for the fire truck to arrive on the scene in golden time(5min) [1]. It has a big difference between the arrival of the fire truck in golden time and over the golden time. The casualties increase of 1.48 times per one fire accident and amount of damage increase of 3.63times if the fire truck doesn't arrive in golden time [2].

In the case of Korea the on-time arrival rate of fire trucks is only 59.3\%. And the on-time arrival rate of Jeonbuk area in Korea is 5\% less then the average rate and ranked very low above all the districts in Korea. These are due to shortage spatial information and lots of narrow roads in these areas [3].

So we targeted this area and progressed the research.

We've realized that vehicle black box install rate was over $88.9 \%$ which shows the high rate of black box usage [4]. So to find the solution for this problem, we used the black box which almost people use, and collect the video by the black box and send it to the server. Then we used the Yolo-v3 algorithm to see if the device could recognize the object and perceive the alley situation [5].

Through this study, we expect the emergency vehicle to be in golden time and minimize the damage. And also this could be helpful for application to the Smart-city system and create a new market that uses the database of spatial big data. Especially we used the mini computer 'Raspberry-pi' and the open source algorithm 'Yolo v3' for image processing. Our goal of this study is shown as Figure 1 below.

\section{Trends of the Study}

\subsection{TCS(Transportation on Control System)}

In Eastern part of U.S. offers signal system. TCS uses GPS system to shorten response time. It make use of real-time road information and location of the emergency vehicle so it makes possible to change the signals

+ Corresponding author. Tel.: + 82-10 85605094

E-mail address: tjsdk7009@gmail.com 
green which is in the optimal path to the scene of the accident [6]. The example of TCS is shown as Figure 2 below.

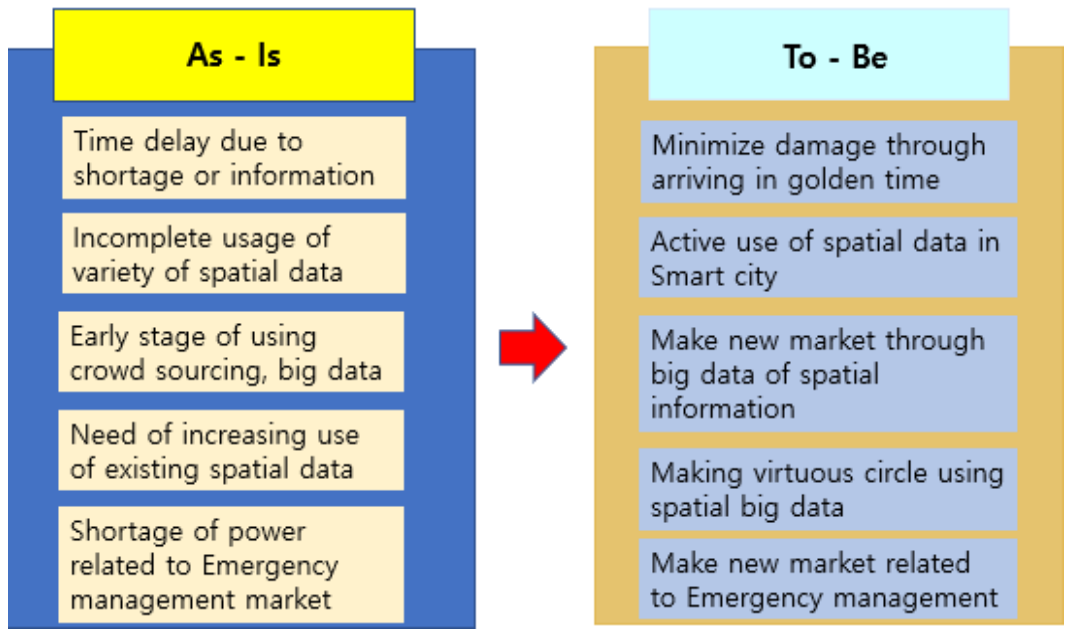

Fig. 1: Goal of this study

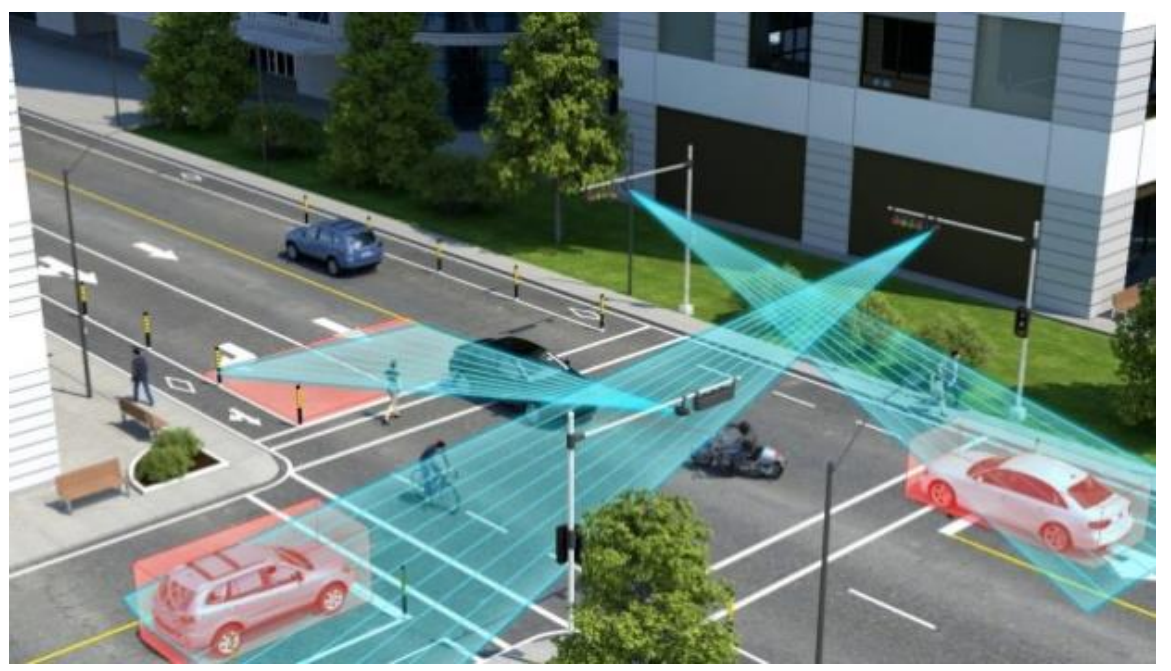

Fig. 2: Transportation on control system (TCS)

\subsection{LBS(Location Based Service) Technology used by Lots of Companies}

Apple is serving Indoor Map and navigation service and the apple map is leading the evolvement of Apple map to the LBS platform. Figure 3 shows the process of APPLE LBS service.

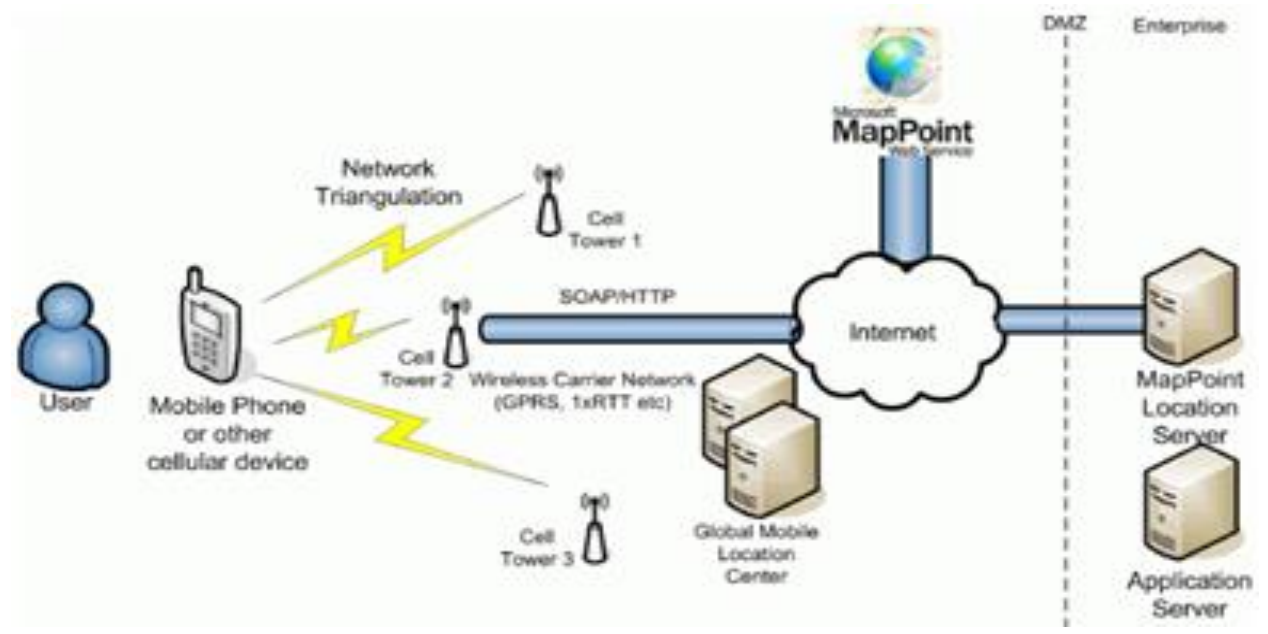

Fig. 3: Composition of APPLE LBS

Google is serving location service by google map. 
HERE is serving LBS map for vehicle, Enterprise and working hard to develop related technology in self-driving car with LG and SKT [7].

\section{Road Information Collecting Device}

\subsection{The Device We Used in the Experiment}

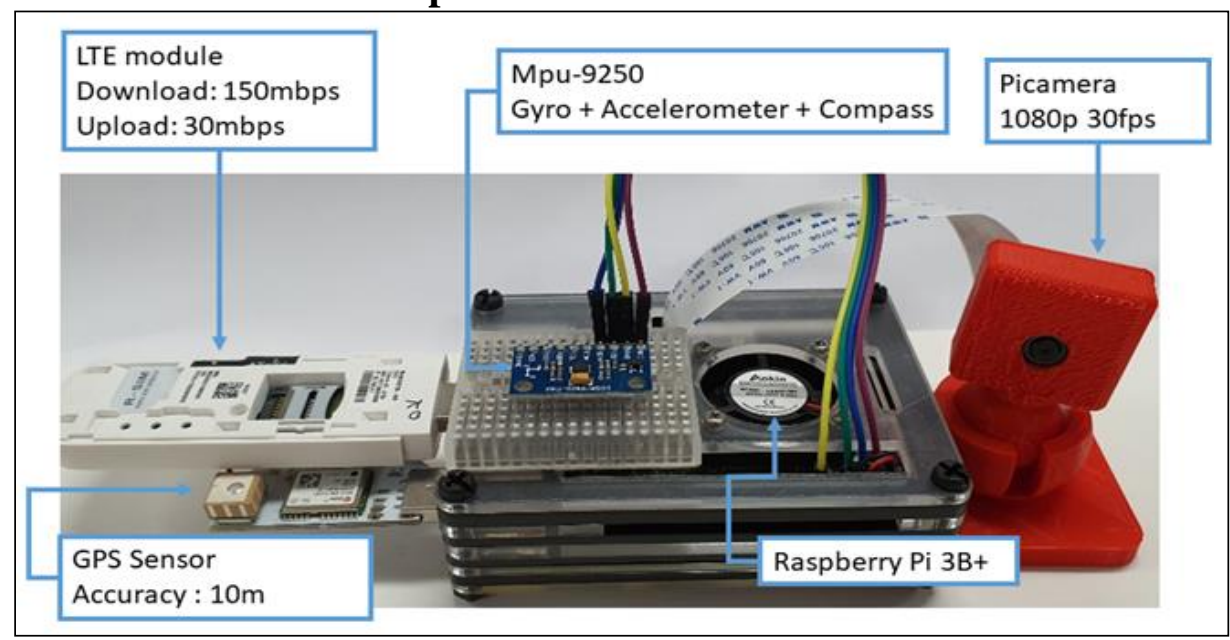

Fig. 4: Black box device used in the experiment

We made the device to have the similar specification of the black box shown as Figure 4. The black box need processor, GPS, position recognition system, camera and additionally we used communication device to communicate with the server. For the whole control, we used raspberry-pi 3B+ [8]. We chose the Raspberry pi because it is more frequently used then other developer devices and we thought it had a sufficient specification to make the black box.

For the camera, we used the Pi-camera that could fit in to the raspberry-pi. Pi camera offers maximum 8MP 3280*2464 Pixel, but these days lot of black box uses 4MP 1920*1080 Pixel, so we lowered the specification of the Pi-camera to fit in to the general black box specification.

Other devices and models are composed as the table 1 below [9].

Table 1: Information of The Device Used In The Experiment

\begin{tabular}{|c|c|c|}
\hline Composition & function & performance \\
\hline $\begin{array}{l}\text { Raspberry Pi } \\
\text { 3B+ }\end{array}$ & $\begin{array}{l}\text { Black box, image processing, } \\
\text { communication }\end{array}$ & $\begin{array}{c}\text { CPU : Quad 1.4GHz } \\
\text { RAM : 1GB SDDRAM } \\
\text { GPIO : } 40\end{array}$ \\
\hline LTE module & $\begin{array}{l}\text { LTE network } \\
\text { communication }\end{array}$ & $\begin{array}{c}\text { Communication velocity : 150mbps } \\
\text { LTE communication band : } \\
\text { Band1(2100MHz)/Band3(1800MHz)/Band28(700MHz) } \\
\text { 3G communication band : } \\
\text { UMTS B1/B5 UMTS }(2100 / 850) \mathrm{MHz}\end{array}$ \\
\hline $\begin{array}{l}\text { GPS Sensor } \\
\quad \text { Neo-06 }\end{array}$ & $\begin{array}{l}\text { Identify the location of the } \\
\text { vehicle, GPS }\end{array}$ & $\begin{array}{c}\text { Accuracy : } 1.8 \mathrm{~m} \\
\text { Search channel : } 66 \\
\text { Trace channel : } 22 \\
\text { Update cycle }: 10 \mathrm{hz}\end{array}$ \\
\hline Mpu-9250 & $\begin{array}{l}\text { Identify the position of the } \\
\text { vehicle through } 9 \text { axis }\end{array}$ & $\begin{array}{c}\text { Voltage } 3.3 \mathrm{v}-5 \mathrm{v} \\
\text { Communication method : I2C, SPI } \\
\text { Gyro : } \pm 25050010002000 / \mathrm{s} \\
\text { Acceleration }: \pm 2 \pm 4 \pm 8 \pm 16 \mathrm{~g} \\
\text { Magnetic }: 4800 \mathrm{uT}\end{array}$ \\
\hline
\end{tabular}




\begin{tabular}{|c|c|c|}
\hline Pi camera & Black box camera module & $\begin{array}{c}\text { Resolution : 1080p 30fps } \\
1920 * 1080 \text { pixsel } \\
\text { Image quality : } 8 \text { million pixel } \\
\text { Viewing angle: }-20^{\circ}-60^{\circ}\end{array}$ \\
\hline Micro SD & Storage & $\begin{array}{c}\text { Storage space }: 128 \mathrm{~GB} \\
\text { Read }: 100 \mathrm{MB} / \mathrm{s} \text { Write }: 100 \mathrm{MB} / \mathrm{s}\end{array}$ \\
\hline
\end{tabular}

\subsection{Operation Process}

Raspberry Pi transmits the data to the server every minute.

The data collected by each devices is composed of (value of GPS(x,y), Pi Camera(pnag, h.264(image extension)), MPU-9250(acceleration, gyro, terrestrial magnetism), Raspberry-Pi network(IP), image(photo,video)) [10]. The Server organize the divided text of the data transmitted from the raspberry pi separately. And analyze the video through the yolo algorithm then store the result. The whole system is shown as Figure 5 below.
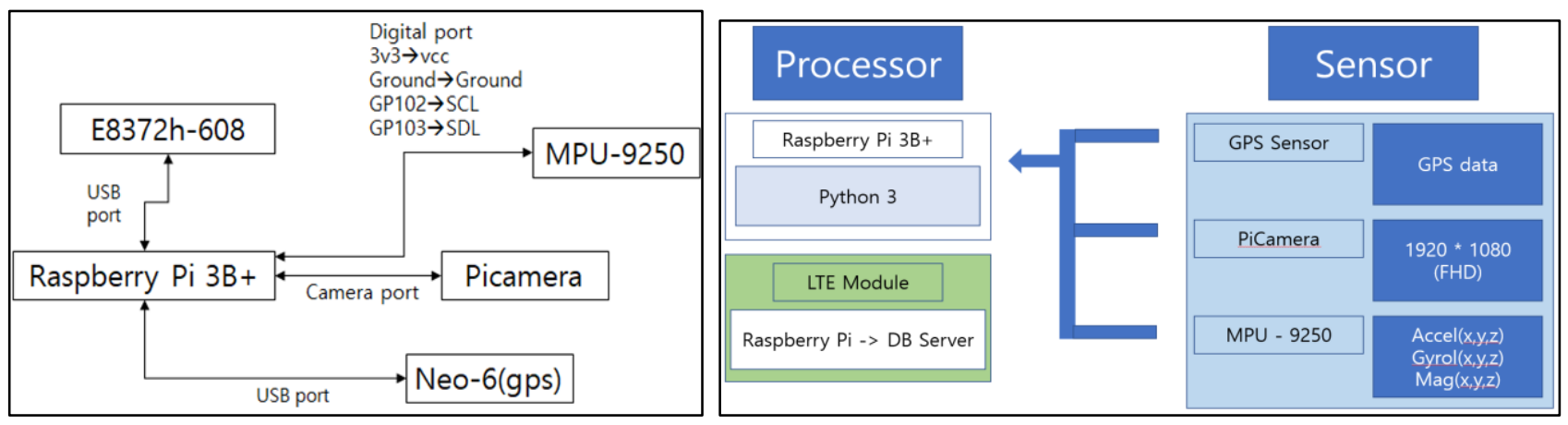

Fig. 5: System configuration

\section{Vehicle Feature Extraction by Deep Learning}

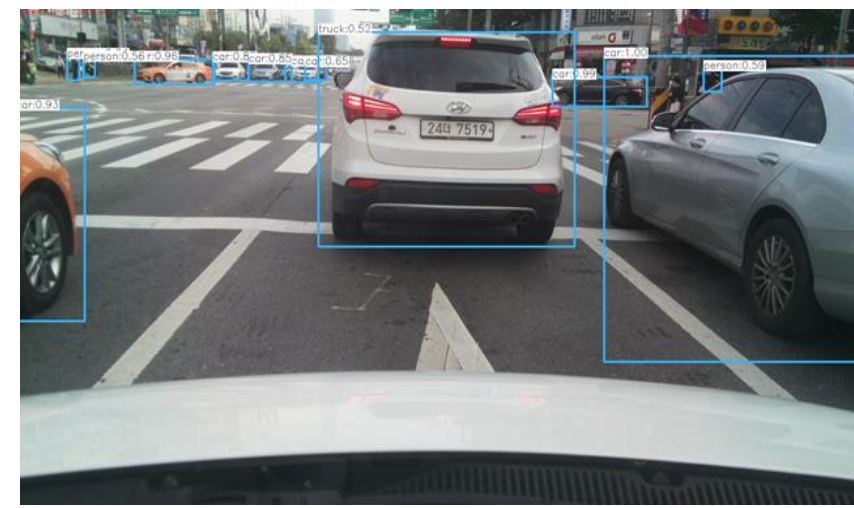

Fig. 6: Extracting vehicle from the road

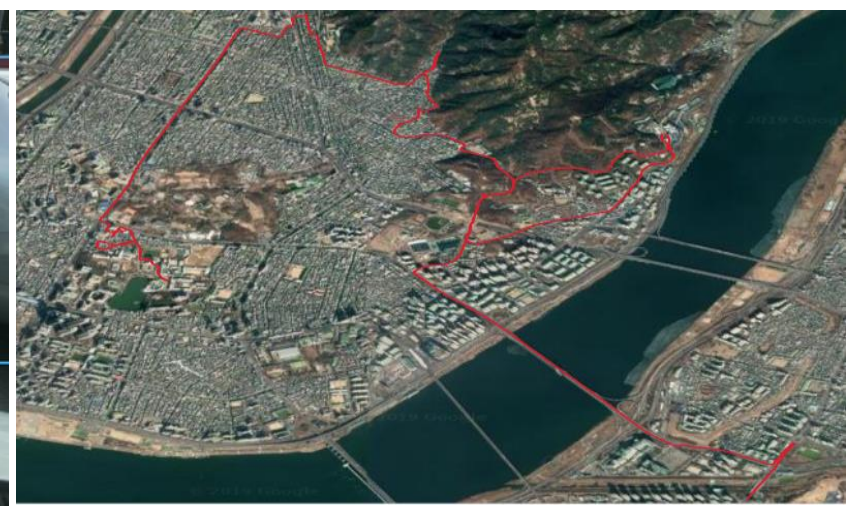

Fig. 7: Route where we collect the traffic data

We've drived over $16.805 \mathrm{Km}$ to collect the traffic data. The image about vehicle extraction and route is shown in Figure 6 and 7 and the device was installed as Figure 8.

We used the Pi camera of the Raspberry pi to transmit FHD resolution file. And we conducted the experiment in 2 ways.

1. Recognizing photos of FHD quality per 30 seconds.

2. Transmitting 5 second length of videos of FHD quality per 45 seconds.

We used the communication module in the raspberry pi to transmit photos and videos. There was a delay in processing to collect and transmit video from the raspberry pi due to the limitation of hardware. To solve this we put 45 second of waiting time for 5 second video so the raspberry pi could have relax time to finish the process. 
In communication, nowadays LTE communication uses private network so at the server to communicate directly with the raspberry pi TCP/IP communication is needed. In this case if the black box is connected with lots of routes, the server communication won't be smooth. So it will be appropriate to use http communication for raspberry-pi to transmit data to the server and the server to check the transmission [11].

Lastly the Raspberry-pi's problem is the micro sd used as storage. There is a limitation of speed for micro sd to read and write the data and it is highly insufficient to overcome the difference of the speed with the CPU. To solve this problem the hardware, especially the memory should be developed.

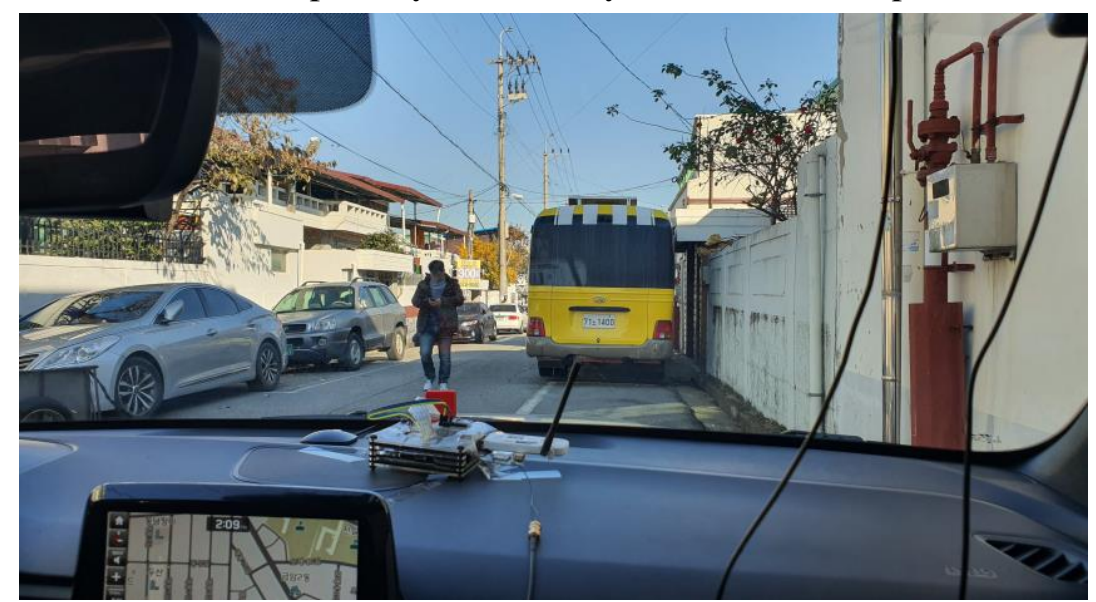

Fig. 8: Device installed in the vehicle

\section{Experimental Result and Perspective}

\subsection{Result}

Through the experiment we could send the video and vehicle data to the server completely by combining the Raspberry-pi and LTE router and was possible to recognize the object by the yolo algorithm as Figure 9 below.

But the video processing took a long time. We think GPU is need to make the process faster.

We expect this could be applied to the emergency vehicle guidance. It can recognize the object and decide whether the vehicle is in the road or not. But it has a limitation of deciding the width of the road and the width of the remaining width excluding the parked vehicles, so we need technology to make those kinds of problems solved.

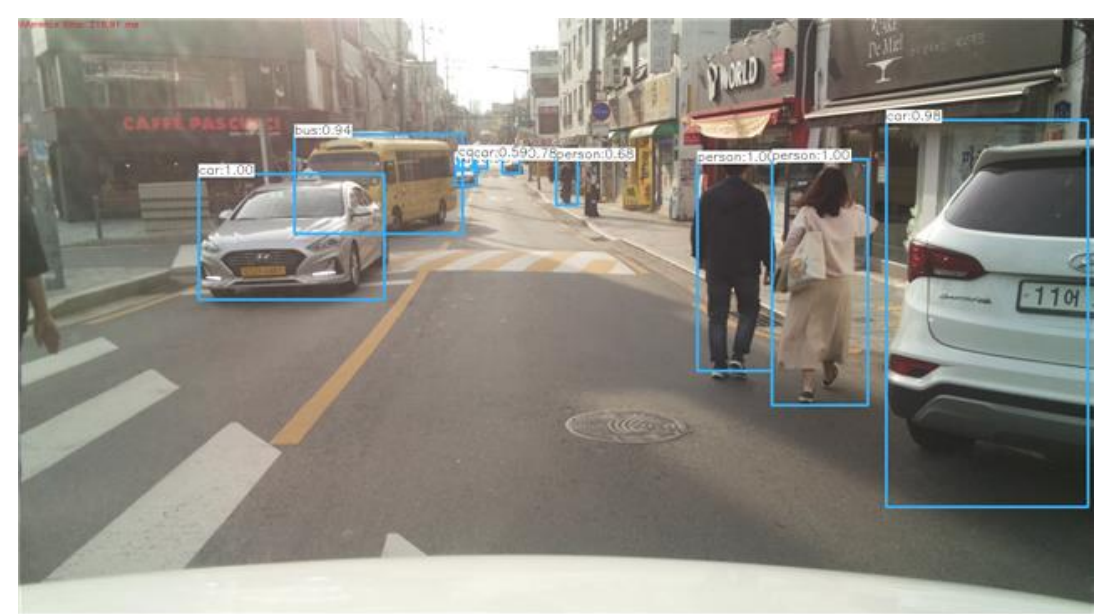

Fig. 9: Object detection through the device

The accuracy of yolo v3 is about $70 \%$ but in our study we've got 1 2\% lower than that. The reason why is because we've took the video at the front side of the vehicle so it had a different angle of view with the existing data. 


\subsection{Ways to Improvement}

It's still insufficient to recognize the affordable width the vehicle can pass through. This is because the variety of form of the alleys, different image composition and the location of the black box. We need more precise and standard black box location and develop the algorithm to recognize the road width.

\section{Conclusion}

We proposed the application of emergency vehicle guidance system using video imagery collected by vehicle black box. It showed a sufficient performance which can distinguish cars and other obstacles clearly. But it still has a limitation of deciding the width of the road and remaining space excluding the parked vehicle.

To solve this issue we need more detail location information and posture of the black box camera and more data of variety of road situation and alleys. Also development of algorithm and GPU are required.

It is meaningful that we can use deep learning in public interests and this may save more lives in emergency situations. GPU and deep learning algorithms are keep being developed so we expect the limitation of this study will be solved within a short time.

\section{Acknowledgement}

"This research was supported by the MISP(Ministry of Science, ICT \& Future Planning), Korea, under the National Program for Excellence in SW(No. 2018-0-00213, Konkuk University) supervised by the IITP(Institute of Information \& communications Technology Planing \& Evaluation)"(No.2018-0-00213, Konkuk University)

\section{References}

[1] Choeung Rae. (2015). "Safe Gyeonggi-do: Securing Golden Time.” Issues \& Diagnosis, (179), 1-25.

[2] Yun-gu Kang "(A)study on factors restrained from fast moving of fire engine : focused on reduction of moving time" Kangwon National University 2016

[3] Ko Eun-hee '64\% 'Arrival within 5 Minutes "Desperate Needs" https://news.joins.com/article/15050078, 2014

[4] Sejin Kim "Installation of car black boxes increases year by year ... installation rate 89\%" http://www.datasom.co.kr/news/articleView.html?idxno=99167. 2019

[5] Shafiee, Mohammad Javad, et al. "Fast YOLO: A fast you only look once system for real-time embedded object detection in video." arXiv preprint arXiv:1709.05943 (2017).

[6] Cheol ki lee, "Emergency vehicle priority signal operation plan", Police Science institute 70p 2014

[7] Korea Internet \& Security Agency "Domestic and foreign LBS industry trend report" 2018

[8] Upton, Eben, and Gareth Halfacree. Raspberry Pi user guide. John Wiley \& Sons, 2014.

[9] Pi, Raspberry. "Raspberry pi 3 model b." Online\}. Tillgänglig: https://www. raspberrypi. org/products/raspberry-pi-2-model-b/\{Använd 1002 2016\} (2015).

[10] Yao, Leehter, et al. "An integrated IMU and UWB sensor based indoor positioning system." 2017 International Conference on Indoor Positioning and Indoor Navigation (IPIN). IEEE, 2017.

[11] Tran, Thien-Toan, Yoan Shin, and Oh-Soon Shin. "Overview of enabling technologies for 3GPP LTE-advanced." EURASIP Journal on Wireless Communications and Networking 2012.1 (2012): 54 